\title{
Experimental Study on Stress and Strain Characteristics of Solidified Clay under Seawater Condition
}

\author{
$W U$ Zhiqiang $^{1,2,}{ }^{*}, C A I$ Zhengyin ${ }^{1,2}, X U \mathrm{Kai}^{1,2}$, GENG Zhizhou ${ }^{1,2}, H U A N G$ Yinghao $^{1,2}$, LI Xiaomei ${ }^{1,2}$ \\ ${ }^{1}$ State Key Laboratory of Hydrology-Water Resources and Hydraulic Engineering, Nanjing 210024, China \\ ${ }^{2}$ Geotechnical Engineering Department, Nanjing Hydraulic Research Institute, Nanjing 210024, China
}

\begin{abstract}
This paper presents the results of a laboratory study on the stress-strain relationship of solidified clay formed in seawater corrosion condition. An automatic triaxial apparatus was used and the axial stress and strain was monitored continuously. The dry density was $1.0 \mathrm{~g} / \mathrm{cm}^{3}$, the cement contents were $4,6,8$ and $10 \%$ by weight of dry soil particles, and the curing time was 28,60 and 90 days respectively. Test results indicate that the stress strain relationship of cemented clay was affected by soil density, cement content and curing period. A behaviour of strain hardening to strain softening occurred with the increase of cement content. Strong structure will form in cemented clay when the admixture content is $10 \%$ or more. The increase in strength of the solidified foundation is resulted from the increase in internal friction angle and cohesive force. The cohesive force increases obviously with the increase of the cement content and the curing age, but the change of internal friction angle is not pronounced after reaching a certain value.
\end{abstract}

\section{Introduction}

Using cement or lime to improve the engineering properties of soil can maximize the use of original soil. And this method has been widely used in foundation treatment [1-3]. With the rapid development of port construction in China, more and more wharfs structures are being constructed at muddy shorelines with poor natural water depth and difficult geological conditions in recent years. When Cement-Deep-Mixing method is used to reinforce the soft layer in the wharf area, the formation and use of cement-soil in the foundation are always in contact with sea water. However, the erosion environment of sea water will cause the change of mineral composition and microstructure of cement-soil, and then lead to the corresponding change of mechanical properties. Therefore, experimental study on the mechanical properties of solidified clay under seawater environment is of practical significance.

Around 2000, scholars have carried out a large number of studies on the influence of clay-water and clay-cement ratio on its strength, compression and permeability properties. Nagaraj, Kasama, and Bergado have studied the compression behaviour of soft clay mixed with cement, and method for calculating the compression curves using the water content, void ratio to cement content ratio is proposed [4-6]. Laboratory tests show out that cement content and curing period are the main factors affecting the strength and deformation characteristics of cement clay. And the shear strength of cemented clay is mainly composed of friction and cementation among particles [7-9]. In recent years, Du, $\mathrm{Yu}$ and Rios pointed out that the hydration products decomposed gradually and the internal structure of solidified soil changes under dry-wet cycling and sulfuric acid corrosion [10,11], which future results in the change of soil strength and deformation characteristics [12-14].

Much work has been done regarding the physical and mechanical properties, while the most up-to-date investigations are limit to the cement clay formed under routine conditions eroded by the change of external environment. The objective of this study is to present the strength characteristics and its changing role of cemented clay formed in environment subjected to ocean erosion, specifically, the stress-strain relationship of cement clay with different cement content and curing period.

\section{Experimental investigation}

\subsection{Site condition and soil sampling}

The clay used in this study was collected from the Xuwei Harbor, which is located on the west coast of Haizhou Bay, the Yellow Sea, China. The site consists of about $12 \mathrm{~m}$ of soft clay overlying a deep silty sand layer which is underlain by sand. The soft clay below the sea floor is Holocene marine sediments, which are often distinguished by their high compressibility and high sensitivity. It is suggested that the marine clay is deposited after the last Ice Age and is usually thought to be younger than 11,700 years. Distinguished from Ariake clay in Japan, eastern Canadian clay and Bangkok clay in South Asia, the collected marine clay is

\footnotetext{
Corresponding author: zqwu@,nhri.cn
} 
characterized by its low liquid limit and different mineral composition.

To avoid impurities in the surface layer, the clay used in this study was collected from $2 \mathrm{~m}$ below the sea bed. According to laboratory particle analysis test results, this soft soil is a type of grey silty clay that is composed of $48.2 \%$ clay, $48.2 \%$ silt, and only $3.6 \%$ sand, and the size distribution cure is shown in Fig. 1. The clay is highly plastic with a natural water content that ranges from $55.8 \%-68.2 \%$. The bulk density and specific gravity $G_{\mathrm{s}}$ of the soil are $\sim 16.0 \mathrm{kN} / \mathrm{m}^{3}$ and 2.72 . The main physical characteristics of the tested soil are presented in Table 1.

Table 1. Physical characteristics of soft marine clay

\begin{tabular}{|c|c|}
\hline Properties & Index value \\
\hline Liquid limit, LL (\%) & 78.5 \\
\hline Plastic value, PL (\%) & 38.2 \\
\hline Liquidity index, LI & 0.62 \\
\hline Clay particle (\%) & 48.2 \\
\hline Silt particle (\%) & 48.2 \\
\hline Sand particle (\%) & 3.6 \\
\hline Main mineral component & llite-montmorillonite mixed- \\
\hline
\end{tabular}

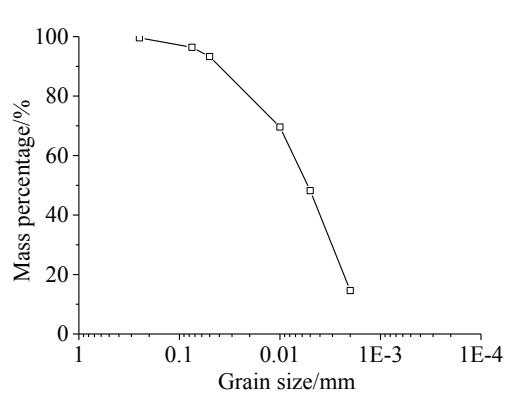

Fig. 1. The grain-size distribution curve

\subsection{Specimen preparation}

The homogeneity and uniformity of the cemented samples are influenced by water sulphate, soil grain-size distribution, and chemistry and sampling method. To ensure the homogeneity of specimens, the adopted sampling procedure was as follows: First, the wet marine clay was air dried and was sifted through a $1.0-\mathrm{mm}$ sieve to remove pieces of shell and other larger particles. In preparing the samples, a specified dry soil density of 1.0 $\mathrm{g} / \mathrm{cm}^{3}$, a water content of $63.2 \%$, cement contents of 4,6 , 8 , and $10 \%$, and a curing time $(T)$ of 28,60 and 90 days were selected. The estimated amount of the base clay was thoroughly mixed with cement slurry by electrical mixer. Then the cement slurry was prepared with the required amount of cement with water. The mixing of the slurry and the clay was done until the mixture was uniformly mixed. At last, the mixed material was placed in a steel mold (39.1 $\mathrm{mm}$ in diameter, $80 \mathrm{~mm}$ in height) in three equal layers. During sampling, the specimen density was monitored carefully and maintained constant. The cement content $\left(a_{\mathrm{c}}\right)$ is defined as the ratio between the dry weight of the cement and the dry weight of the soil particles in this paper.

The prepared sample was soaked in water in a $97 \%$ humidity room at 25 centigrade until the lapse of the different planned curing times. It should be noted that the water used in this study is collected from the engineering site to make sure that the chemistry of the water is similar to that of the pore water in its natural state. And the cemented used is a special kind of cement which was designed for ocean engineering.

\subsection{Testing methodology}

Laboratory drained shear test was carried out. And the vertical displacement rate in the test was $0.008 \% / \mathrm{min}$. The effective confining pressures were 100, 200, 300 and $400 \mathrm{kPa}$. The axial stress, vertical deformation was collected and proposed automatically by computer during the entire process of the test. The test scheme is shown in Table 2.

Table 2. Test scheme

\begin{tabular}{|c|c|c|c|c|}
\hline $\begin{array}{c}\boldsymbol{\rho}_{\boldsymbol{d}} \\
\left(\mathbf{g} / \mathbf{c m}^{\mathbf{3}}\right)\end{array}$ & $\boldsymbol{w}(\mathbf{\%})$ & $\boldsymbol{a}_{\mathbf{c}}(\mathbf{\%})$ & $\begin{array}{c}\text { Confining } \\
\text { pressure } \\
(\mathbf{k P a})\end{array}$ & $\boldsymbol{T}$ (days) \\
\hline 1.0 & 63.2 & 4,6, & 100,200, & 28,60, \\
8,10 & 300,400 & 90 \\
\hline
\end{tabular}

\section{Stress-strain characteristic}

The strength formation process of cemented clay formed in seawater surroundings is quite different to that in freshwater due to the existence of salt in the pore water. The effect of different factors on the stress-strain characteristics are discussed as follows.

\subsection{Soil sample}

To investigate the influence of cement content on the stress-strain relationship of cemented clay, a drained shear test was conducted. The relationship between deviatoric stress and axial strain is shown in Fig. 2.

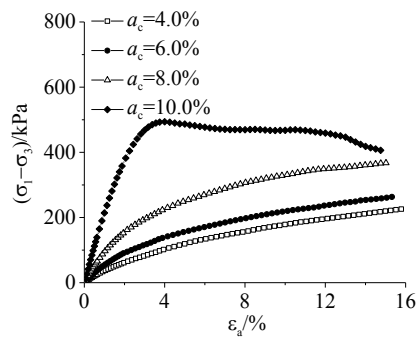

(a) $\sigma_{3}=100 \mathrm{kPa}$ 


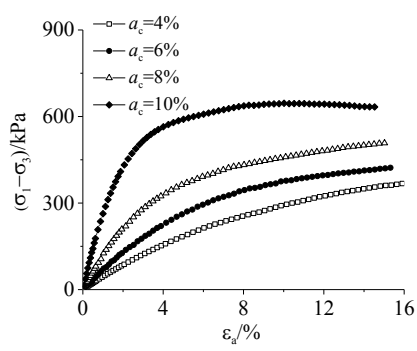

(b) $\sigma_{3}=200 \mathrm{kPa}$

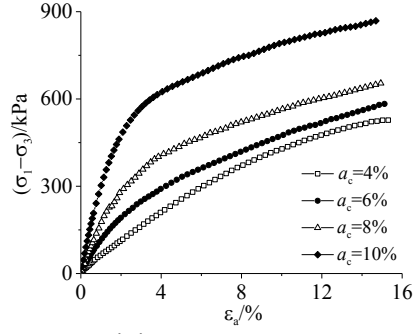

(c) $\sigma_{3}=300 \mathrm{kPa}$

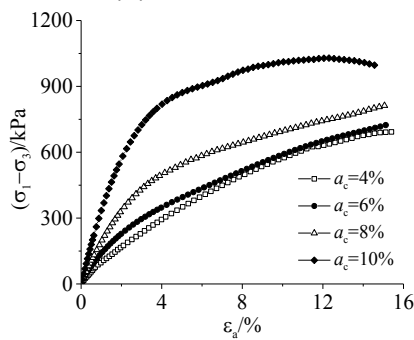

(d) $\sigma_{3}=400 \mathrm{kPa}$

Fig. 2. Stress-strain relationship for cemented clay with different cement content $(T=28$ days $)$

The common characteristic of cement Lianyungang marine clay with a curing period of 28 days is shown in Fig. 2. The test results show out that the cement content has a significant effect on the stress-strain relationship of solidified soft clay. It can be seen from Fig. 2 that the stress-strain curve is a typical strain harden type with a cement content of 4,6 , and $8 \%$. The deviatoric stress increases with the increase of axial strain. And the specimens demonstrate a plastic failure mode with some similar properties of normal consolidated clay finally. The strain softening begins to show and the deviatoric stress peaks with the increase of axial strain for specimens with a cement content of $10 \%$. It can also be seen from Fig. 1 that the failure strength increases with the increase of cement content. Taking the test curves under confining pressure of $100 \mathrm{kPa}$ as an example, the failure strength at different cement content was 165.9 $\mathrm{kPa}, 219.6 \mathrm{kPa}, 260.7 \mathrm{kPa}$ and $408.2 \mathrm{kPa}$.

The drained shear test results show out that the deviatoric stress increases with axial strain under marine environment when the cement content is less than or equal to $8 \%$, which is similar to the strength and deformation behaviour of normally consolidated clay. Test results indicate that there is no strong structure formed among the soil particles, and the strength of soil is mainly affected by external stress [15]. A peak value of deviatoric stress appears with the increase of axial strain at a cement of $10 \%$, indicating that a brittle failure pattern for cemented clay during shear with a cement content is more than or equal to $10 \%$. And this means the hydration products gradually cemented the soil particles together and a strong soil structure formed.

\subsection{Curing period}

The relationship between deviatoric stress and axial strain at different curing times is shown in Fig. 3.

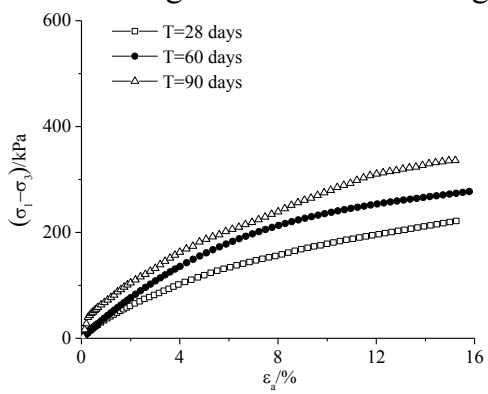

(a) $\sigma_{3}=100 \mathrm{kPa}$

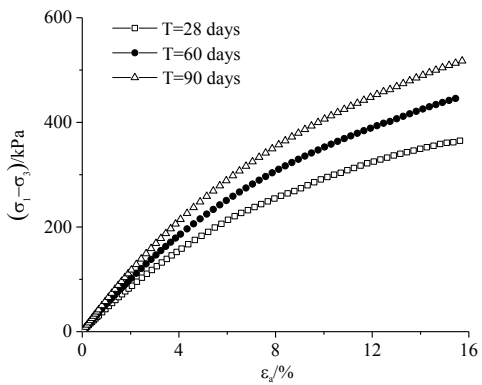

(b) $\sigma_{3}=200 \mathrm{kPa}$

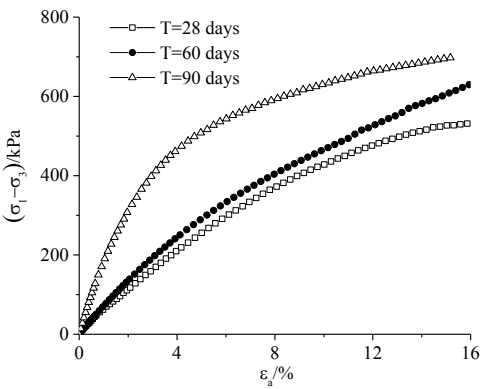

(c) $\sigma_{3}=300 \mathrm{kPa}$

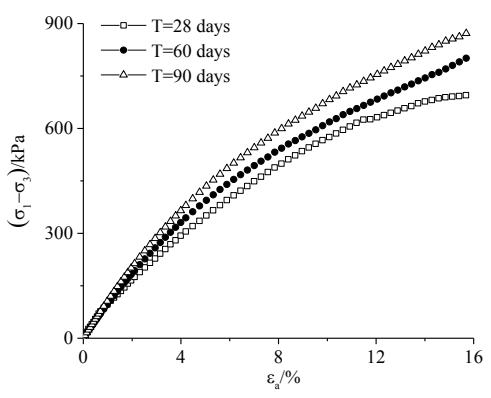

(d) $\sigma_{3}=400 \mathrm{kPa}$

Fig. 3. Stress-strain curves with different curing period $\left(a_{\mathrm{c}}=4 \%\right)$

It could be seen from Fig. 3 that the deviatoric stress increases with axial strain at different curing period and indicating a strain hardening characteristic. It can also be seen from Fig. 3 that the strength increases with curing period. And the stress-strain pattern of cemented clay under marine environment will not change significantly with the increase of curing time after 28 days of curing. 
The strength increasing mechanism of cemented clay is as follows: the amount of hydration products increases and hardens gradually with the increase of curing time, which enhances the particle bonding among the soil particles and then the shear strength increases.

\subsection{Confining pressure}

Fig. 4 gives the stress-strain relationship of cemented clay under different confining pressure. It can be seen form Fig. 4 that the confining pressure has certain effect on the strength behaviour of cemented clay.

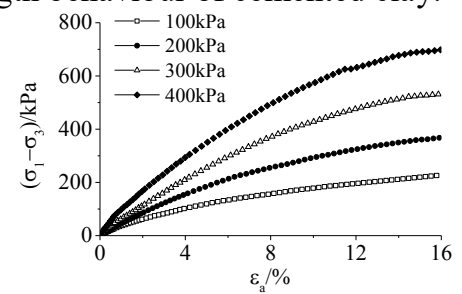

(a) $\quad a_{\mathrm{c}}=4 \%$

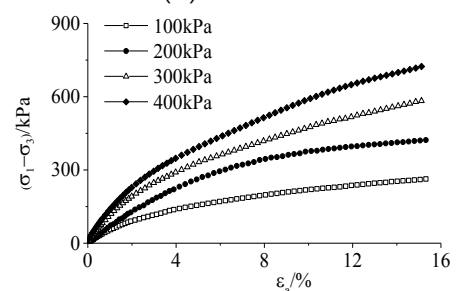

(b) $a_{\mathrm{c}}=6 \%$

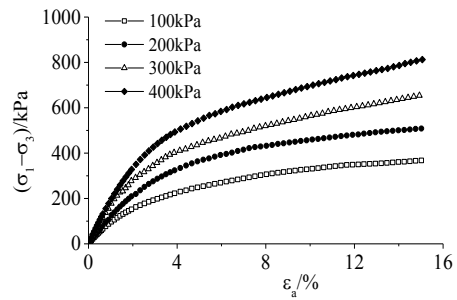

(c) $a_{\mathrm{c}}=8 \%$

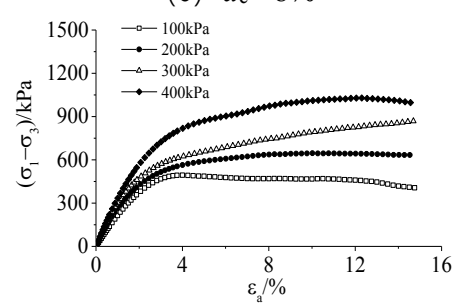

(d) $a_{\mathrm{c}}=10 \%$

Fig. 4. Stress-strain relationship with different confining pressure $(\mathrm{T}=28$ days $)$

Fig. 4 indicates that the stress-strain curves of the specimens under different confining pressures show out strain hardening pattern with cement content of 4, 6 and $8 \%$. But, deviatoric stress peaks and demonstrates a strain softening characteristic when the cement content is $10 \%$ under a confining pressure of $100 \mathrm{kPa}$. While the strain softening phenomenon disappears with the increase of confining pressure.

As a typical kind of artificial modified soil, the strength of cemented clay mainly comes from the filling of pores by hydration products and the cementation bonds among soil particles. The hydration products are mainly used to fill the pores between the particles at low density. The soil skeleton compresses under confining pressure and demonstrates strain hardening phenomenon. The hydration products are mainly used to enhance the cementation bonds among soil particles when the cement content is high. Therefore, compressive strength is less affected by the confining pressure before yield.

\section{Shear strength characteristics}

The stress-strain curves of cemented clay are arranged, and the shear strength parameters of the samples are obtained according to the Mohr-Coulomb failure criterion. Cohesive force, internal friction angle and their variation laws are shown in Fig. 5 and Fig. 6.

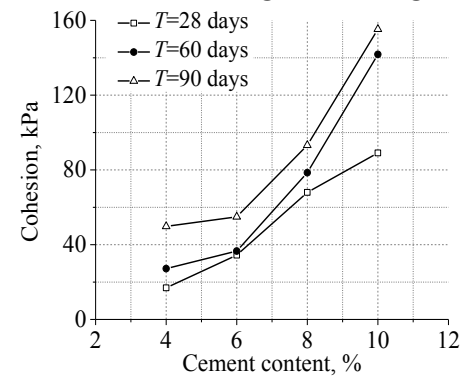

Fig. 5. Change of cohesion with cement content

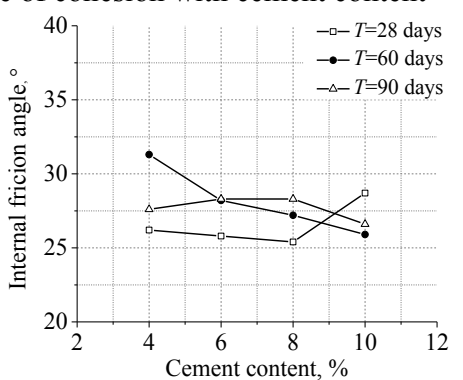

Fig. 6. Change of internal friction angle with cement content

Fig. 5 gives the test results of cohesive force and its change law of cemented clay at different conditions. By the experiment data we can see that the cohesive force increases sharply with cement content. When the curing age is 28 days, the cohesive force increases from 16.9 $\mathrm{kPa}$ to $89.1 \mathrm{kPa}$. When the curing age is 60 days, the cohesive force increases from $27.2 \mathrm{kPa}$ to $141.8 \mathrm{kPa}$. And when the curing age is 90 days, the cohesion increases from $49.8 \mathrm{kPa}$ to $155.3 \mathrm{kPa}$.

As can be seen from Fig. 6, the test data still demonstrate the following characteristics although there is a certain degree of discreteness: the internal friction angle varies from 25 to 35 degrees with the increase of cement content from $4 \%$ to $10 \%$ under the curing time of 28 days, 60 days and 90 days. According to pre-field exploration, the effective internal friction angle of undisturbed clay is about 0.9 degrees, and it increases significantly after mixed with cement. While the increasing trend is not pronounced after the internal friction angle reaching a certain value.

Based on the experimental data, the following conclusion can be drawn: the strength increase of cemented clay is resulted from the increase of internal friction angle and the cohesive force. When the cement 
content is low, the hydration products mainly adheres to the surface of the soil particles and fills the pores between the particles. And the density of the soil increases compared with that of the raw soil, showing the increase of internal friction angle [16-17]. As the cement content increases, the hydration products gradually bind the soil particles to form a large cluster, which exhibits a strong cementation effect and thus exhibits an increase in cohesive force.

\section{Conclusions}

In this paper, the stress-strain characteristics of cemented clay formed in seawater surroundings is studied experimentally. The conclusions are as follows:

(1) The stress-strain characteristic of solidified marine clay is affected by soil density, cement content and curing period. The stress-strain behavior gradually change from strain hardening to strain softening with the increase of cement content.

(2) The strength formation of solidified marine clay under sea water corrosion environment is different from that under normal conditions. There is no strong structure formed in the soil and the strength of the soil is mainly affected by eternal stress when the cement content is less than or equal to $8 \%$. While the stressstrain curve peaks and shows similar characteristics with that of over-consolidated soil with a cement content is greater than or equal to $10 \%$.

(3) The strength increases of the solidified marine clay result from the increase in internal friction angle and cohesive force. The cohesion force increases significantly with the increase of cement content and curing period, but the increase of internal friction angle is not that obvious after reaching a certain value.

This work has been supported by the Central Publicinterest Scientific Institution Basal Research Fund and National Natural Science Foundation by the Chinese government (NO. Y318001, NO. Y318011, No. 51879167). This support is greatly appreciated. The authors also thank those who provided technical support in the laboratories from the State Key Lab of Hydrology-Water Resources and Hydraulic Engineering and Department of Civil Engineering.

\section{References}

1. Mitchell J K. Practical problems from surprising soil behavior, J. Geotech. Eng., 112(3): 259289(1986)

2. A A, Barclay R T, Casias T J E A. State-of-theart report on soil cement, ACI Mater J., 87(4): 395-417(1990)

3. Bergado D T, Anderson L R, Miura N, et al. Soft ground improvement in lowland and other environments[C]. ASCE, 1996

4. Nagaraj $T$, Pandian $N$ S, Raju $P$. Compressibility behaviour of soft cemented soils, Geotechnique, 48(2): 281-287(1998)
5. Bergado D T, Taechakumthorn C, Lorenzo G A, et al. Stress-deformation behavior under anisotropic drained triaxial consolidation of cement-treated soft Bangkok clay, Soils and Found., 46(5): 629-637(2006)

6. Kasama K, Zen K, Iwataki K. Undrained shear strength of cement-treated soils, Soils and Found., 46(2): 221-232(2006)

7. Vatsala A, Nova $R$, Murthy B. Elastoplastic model for cemented soils, J. Geotech. Geoenviron. Eng., 127(8): 679-687(2001)

8. Horpibulsuk S, Miura N, Bergado D $T$. Undrained shear behavior of cement admixed clay at high water content, J. Geotech. Geoenviron. Eng., 130(10): 1096-1105(2004)

9. Horpibulsuk S, Miura N, Nagaraj T S. Claywater/cement ratio identity for cement admixed soft clays, J. Geotech. Geoenviron. Eng., 131(2): 187-192(2005)

10. Han Pengju, Bai Xiaohong, Zhao Yoongqiang, et al. Experimental study on strength of cement soil under $\mathrm{Mg}^{2+}$ and $\mathrm{SO}_{4}{ }^{2-i n t e r a c t i o n}$ influence, Chinese J. Geotech. Eng., 31(1): 72-76(2009)

11. Han Pengju, Liu Xin, Bai Xiaohong. Effect of sodium sulfate on strength and micropores of cemented soil, Rock and Soil Mechanics, 35(9): 2555-2561(2014)

12. Du, Yan-Jun, Bo, Yu-Lin, Jin, Fei, et al. Durability of reactive magnesia-activated slagstabilized low plasticity clay subjected to drying-wetting cycle, Eur J Environ Civ En., 20(2): 215-230(2016)

13. Yu, Bo-Wei, Du, Yan-Jun, Jin, Fei, et al. Multiscale study of sodium sulfate soaking durability of low plastic clay stabilized by reactive magnesia-activated ground granulated blast-furnace slag, J Mater Civil Eng., 28(6): 2016(2016)

14. Rios, Sara, Ramos, Catarina, Viana Da Fonseca A, et al. Mechanical and durability properties of a soil stabilised with an alkali-activated cement, Eur J Environ Civ En., 6: 1-23(2017)

15. HONG Zhen-shun, LIU Song-yu, YU Xiao-jun. On destructuration of structured soils, Rock and Soil Mechanics, 25(5): 684-687(2004)

16. Horpibulsuk S, Miura $N$, Nagaraj $T S$. Assessment of strength development in cement-admixed high water content clays with Abrams' law as a basis, Geotechnique, 53(4): 439-444(2003)

17. HUANG Ying-hao, ZHU Wei, DONG Chan, et al. Experimental study on structural behaviour of solidified dredged material, SHUILI XUEBAO, 45(S2): 130-136(2014) 